\title{
The relationship of the green bond and the Social Development Goals (SDGs) targets: a case study of Vigeo Eiris
}

\author{
Dodik Siswantoro ${ }^{1, *}$ \\ ${ }^{1}$ Accounting Department, Universitas Indonesia, Depok, 16424, Indonesia
}

\begin{abstract}
Only Vigeo Eiris relates the green bond initial assessment with the Social Development Goals (SDGs) targets. Thus, this research would analyse the Vigeo Eiris' opinion about the relationship of the green bond and SDGs targets. This would create new insights into the green bond opinion, as other second independent reviews do not propose these issues in the beginning. The research method employs a qualitative method using opinion report of the green bond by Vigeo Eiris after SDGs were launched. However, before SGDs were launched, this agency did not relate to Millennium Development Goals (MDGs), which actually the former action of SDGs. The result showed that the green bond has important roles to mitigate Greenhouse Gases (GHG). In addition, the direct targets to SGDs are mostly 7 aspects. Affordable and clean energy (12 points); 13. Climate Action (9 points); 12. Sustainable Consumption \& Production ( 8 points); 9. Industry, Innovation, \& Infrastructure; and 11. Sustainable Cities \& Communities (7 points respectively) of the total 19 sample. However, the main issues are that there is no clear quantitative target for these SDGs targets and not all issuers have SDGs targets (14 out of 19 samples)
\end{abstract}

\section{Introduction}

Green bonds have contributed much to facilitate some programs to reduce Greenhouse Gases (GHG). Many programs have been launched to reduce GHG. Therefore, green bonds have a significant role to finance such related programs to reduce GHG. Before issuing green bonds, the project proposal from the issuer would be independently reviewed. Only Vigeo Eiris attaches SDGs issues in the green bond assessments in the beginning. However, in the previous issues of SDGs were the Millennium Development Goals (MDGs) were not attached. SDGs have similar to green bonds issues.

The objective of this paper is to analyse Vigeo Eiris' opinion about the relationship of the green bond and SDGs targets. The emphasis and relationship of SDGs to the green bond opinions is a new issue, as other independent reviewers do not conduct it at initial stage. In addition, this paper relates to sustainability reporting and labelling for business which can be paralleled to SDGs. Reporting on SDGs relationship is also important aspects as well. The paper would start from introduction, literature reviews, method, analysis, and conclusion.

\footnotetext{
* Corresponding author: dodik.siswantoro@ui.ac.id
} 


\section{Literature Review}

Papers or researches on the attachment and relationship green bond opinion and SDGs are rare. The discussion of the issue was initially proposed by Climate Bond Initiative (CBI) [1]. However, this relates to United Nation (UN), which proposes SDGs as a goal for bonds. In fact, the green bond itself may have interconnection to SDGs issues. Then, it is a proposal to be called SDGs bonds [7]. However, this may aligned with climate bonds which have independent review [4]. This bond may have benefited to climate change issues [5].

Climate change issues, however, have interdepend to other sectors, for example, climate mitigation is independent (target 13). However, it may affect other targets such as no poverty (SDG1), food security (SDG2) and even health (SDG3). The analysis is if climate change worsens so was the poverty, as well as food security and health [1]. Climate mitigation can be called the most important aspect actually in SGDs in relation to green bonds goals. SDGs bond itself has a framework to be referred [ 8].

Of the 17 targets of SDGs, 6 targeted to climate action (SDG13), affordable and clean energy (SDG7), clean water \& sanitation (SDG6), industry innovation \& infrastructure (SDG9), life on land (SDG15), and sustainable cities (SDG11) [1]. In general, green bonds were allocated to climate action (SDG13) as it is the core purpose of the green bond. From Table 1 and Figure 1, we can see that affordable and clean energy (SDG7) has the biggest portion of green bonds allocation, followed by industry innovation \& infrastructure (SDG9) (39\%). SDG9 for green bond focus on low-carbon buildings (24\%) and low-carbon transport $(15 \%)$. Sustainable cities (SDG11) may relate to SDG9 for sustainability then clean water and sanitation (SDG6) and climate action (SDG13).

Table 1. Allocation of green bonds related to SDGs.

\begin{tabular}{|l|c|}
\hline \multicolumn{1}{|c|}{ SDGs } & \% \\
\hline Climate action (SDG13) & \\
\hline Affordable and clean energy (SDG7) & 40 \\
\hline Industry innovation \& infrastructure (SDG9) & 39 \\
\hline Clean water \& sanitation (SDG6), & 11 \\
\hline Life on land (SDG15) & 3 \\
\hline Sustainable cities (SDG11) & \\
\hline
\end{tabular}

The aforementioned discussion reveals that SDG11 and SDG13 are inherently included in the case of green bonds. Therefore, the correlation of green bond allocation and SDGs targets may not have a clear relationship as they have different target allocations. Alignment between green bond and SDGs should be elaborated and discussed further to attract investors' participation in the green bond. In addition, the issue of climate change and SDGs relationship can be overcome.

The issue of climate change can affect other sectors in SDGs. It serves as the basic issue that should be prioritized before focusing on other sectors in SDGs. This, however, becomes the main issue in green or climate bond issues. The proposal to issue SDG bond by CBI can be an interesting issue but the target for both of them must be synchronized. It is equally important to determine the method of target achievement and measurements for each SDG aspect. 


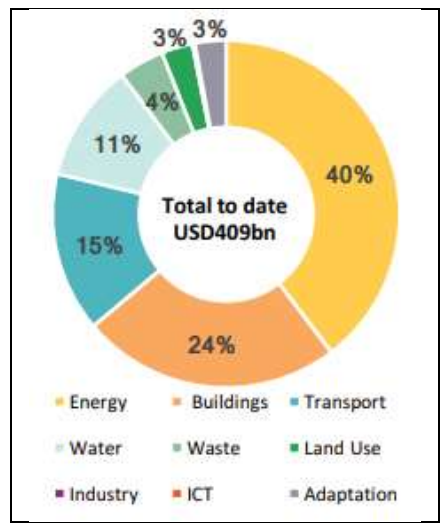

Fig. 1. Use of Green Bond Proceed [1].

\section{Research method}

This research is based on secondary data of Vigeo Eiris' second opinion in 2017-2018. Vigeo Eiris is the first independent review that adopted SDGs aspects for the green bond opinion. They are based in Europe and focuses on environmental, social and governance (ESG) issues.

The total sample consisted of 19 green bond opinions reviewed by Vigeo Eiris. The SDGs analysis started in early 2017. Only 14 opinions attached to SDGs aspects.

\section{Analysis}

From table 2 we can see some big differences between CBI and Vigeo Eiris SGDs targets. Climate action (SDG13) is not the main target of SDGs of green bond allocation, which actually promotes climate change mitigation while Affordable and clean energy (SDG7) only places $22.22 \%$ for Vigeo Eiris, which is lower than CBI's rate of $40 \%$. Sustainable cities (SDG11) is also emphasised by Vigeo Eiris' opinion (12.96\%), but it is not in CBI's.

In fact, Vigeo Eiris has many SGD aspects in green bond assessment. The SGD targets which are not discussed by CBI are:

1. Responsible consumption and production (SDG12) (14.81\%)

Each institution has specific objective which trying to relate the SGD target as follows:

a. Engie - to (re)finance defined efficiency projects on energy and natural resources Preservation

b. Iberdrola - to achieve the sustainability and natural resources efficiency

c. TLFF - to create sustainable practices; and to assist developing countries creating sustainable ways of consumption and production by strengthening scientific and technological capacity

d. Intesa Sanpolo - to (re)finance defined energy efficiency loans

e. RATP - to reduce waste generation in minimizing some impacts on human health and the environment

The issue of efficient production and consumption can be interesting issues. SDG12 takes a role in this aspect. In fact, the area may be very wide as efficiency has a broader meaning. The important issue is how to measure the achievement of the aspect. 
2. Life below water (SDG14) (3.7\%)

NYK has objective - to prevent and reduce pollution in marine by 2025.

Marine pollution is also an important aspect. However, only few institutions deals with this issue. However, this may have a direct effect on climate change but primarily it has an effect on sustainability of resource.

Table 2. Comparison of green bonds allocation related to SDGs.

\begin{tabular}{|l|c|c|}
\hline \multicolumn{1}{|c|}{ SDGs } & \% CBI & \% VI \\
\hline Clean water \& sanitation (SDG6), & 11 & 5.56 \\
\hline Affordable and clean energy (SDG7) & 40 & 22.22 \\
\hline Decent work and economic growth (SDG8) & n.a & 1.85 \\
\hline Industry innovation \& infrastructure (SDG9) & 39 & 12.96 \\
\hline Sustainable cities (SDG11) & n.s & 12.96 \\
\hline Responsible consumption and production (SDG12) & n.a & 14.81 \\
\hline Climate action (SDG13) & Major & 16.67 \\
\hline Life below water (SDG14) & n.a & 3.7 \\
\hline Life on land (SDG15) & 3 & 7.41 \\
\hline Partnership for the goals (SDG17) & n.a & 1.85 \\
\hline
\end{tabular}

n.s $=$ not stated, $n . a=$ not available

3. Decent work and economic growth (SDG8) (1.85\%)

TLFF has objective - to improve an efficiency in consumption and production and to avoid environmental degradation growth, and to achieve full employment

The issue of the workforce may not be related to green or climate change. However, if it is related to environmental workforce, this can be good for the development of one country.

4. Partnership for the goals (SDG17) (1.85\%)

TLFF has objective - to increase partnership for sustainable development globally among multi-stakeholder partnerships by sharing knowledge, expertise, technology and financial resources for the achievement of the sustainable development goals in some developing countries.

Cooperation to improve knowledge on efficient energy usage and sustainable development is relevant to green and climate change issues. However, there should be a clear measurement for the case.

There should be a clear definition for independent reviews when they classify the aspects of SDGs in the case of green or climate bonds. Too wide coverage can be a problem to target the SDGs aspect. Therefore, the issue of measurement can be important. Without a clear measurement to target SDGs aspect, this may not be useful, as investors would like to know 
how the issuers could achieve such a target. CICERO review can be included to calculate green bond level [6]. In addition, ICMA has provided some parameters of SGDs targets [9].

\section{Conclusion}

The classification of green bond allocation to SDGs by CBI may not be relevant as each issue may have specific purposes or projects. In addition, a specific name like SDGs bond may be appropriate as it has a specific target. However, there should be a clear target for each SDGs and a clear method of how the achievements are measured.

\section{References}

1. Climate Bond Initiative (CBI). Green Bonds: A Bridge to SDGs - Focus on SDG 6, 7, 9 , $11,13 \& 15$ (2018).

2. Climate Bond Initiative (CBI). Green bonds as a bridge to the SDGs (2018).

3. F. Leone. Climate Bonds Initiative Launches Briefing Series on SDGs and Green Bonds URL : $\quad$ http://sdg.iisd.org/news/climate-bonds-initiative-launches-briefing-series-onsdgs-and-green-bonds/

4. J. A. Mathews, S. Kidney, K. Mallon, M. Hughes, Energy Policy 38 (2010).

5. M. Więckowska. Copernican Journal of Finance \& Accounting 2, 1 (2012).

6. CICERO. Second Opinions on Green Bonds (2017).

7. E. Frimpong Boamah, D. Osei, T. Yeboah. Development in Practice 27, 4 (2017).

8. BBVA. Sustainable Development Goals (SDGs) Bond Framework (2018).

9. ICMA. Green and social bonds: A high-level mapping to the Sustainable Development Goals (2018). 